\title{
Composite Column Tests - Database and Comparison with Eurocode 4
}

\author{
C. D. Goode*a \\ ${ }^{a}$ Formerly Senior Lecturer in Civil Engineering, The University of Manchester, UK. (Retired) \\ *corresponding author, e-mail address: cdgoode@mypostoffice.co.uk
}

\begin{abstract}
The database of 1819 tests on concrete-filled steel tube columns was reported in 2008 $[1,2]$ and covered all tests traced by the author up to 2007 . This paper reports on 473 more tests carried out by 26 researchers between 2007 and 2017. These have been divided into short and long circular section columns, rectangular section columns, and also into those subjected to axial load and those with an eccentric load (causing an end moment), and collected into a new database. The results are compared with the provisions of Eurocode 4 (EC4) and show the overall average ratio of Test failure load to EC4 prediction for these 473 tests is 1.10 . Eurocode 4 is thus a very reasonable predictor of the failure load and can be used with confidence to design composite columns. The detailed data can be accessed on the 'web', which also contains references to the 51 papers from which the data has been extracted; it will be of use to researchers of composite columns who wish to compare any theoretical analysis they produce with test data.
\end{abstract}

Keywords: Composite; Columns; Tests; Database; Eurocode 4.

\section{Introduction}

This paper continues the work reported in [1], and available in the database [2] (which covered tests up to 2007), by analyzing the tests on 473 concrete-filled steel tubes carried out since 2007. The tests are divided into groups covering circular sections and rectangular sections with and without an applied moment.

The previous work by the author $[1,2]$ covered 1819 tests reported in the literature up to the year 2007. As well as providing a database so that other researchers can compare their theories against these 1819 tests on composite columns, the failure load (Test) in each test was compared with the proposals in Eurocode 4 (EC4) [3]. They showed that Eurocode 4 can be used with confidence for the design of concrete-filled steel tube columns (CFST); the average Test/EC4 being 1.11 for those 1808 columns which satisfied the Code conditions. However, $17 \%$ of these tests failed below the resistance predicted by the Code and this may be thought unacceptable.

The 473 tests reported in this paper show a similar result with, for these 473 tests, the average Test/EC4 prediction being 1.10.

\section{Notation}

$\mathrm{D}=$ Outside diameter of a circular steel tube $\mathrm{h}=$ Larger dimension of a rectangular section $\mathrm{b}=$ Smaller dimension of rectangular section

$\mathrm{t}=$ Thickness of the steel tube

$\mathrm{f}_{\mathrm{y}}=$ Steel yield strength

$\mathrm{E}_{\mathrm{s}}=$ Modulus of elasticity of steel; $200 \mathrm{GPa}$ is assumed when $\mathrm{E}_{\mathrm{s}}$ was not reported

$\mathrm{f}_{\text {cyl }}=$ Concrete cylinder strength; taken as $0.8 \mathrm{f}_{\text {cu }}$ when cube strength was given

$\mathrm{E}_{\mathrm{c}}=$ Modulus of elasticity of the concrete; teken as $\mathrm{E}_{\mathrm{c}}=22 *\left(\left(\left(\mathrm{f}_{\mathrm{cyl}}+8\right) / 10\right)^{0.3}\right.$ if not given by the researcher

$\mathrm{L}=$ Length of the column

$\mathrm{e}_{\mathrm{t}}, \mathrm{e}_{\mathrm{b}}=$ eccentricity of the load at the top and bottom of the column respectively

Test $=$ Test failure load

EC4 $=$ Failure load given by Eurocode 4 with material partial safety factors as unity 


\section{Database}

Most of the data in the database has been obtained from the comprehensive reports of Mark Denavit and his co-workers at the University of Tennessee [4]. Where data was given in imperial units (inches, tons, etc.) it has been converted to metric units (mm, Newtons etc.) in the database reported in this paper. It provides Excel files for short (L/D or $\mathrm{L} / \mathrm{b}<4$ ) and long concrete-filled steel tube circular section column tests without and with moment and similarly for columns with a square or rectangular section. Thus this new database provides a useful reference to all tests on composite columns reported between 2007 and 2017 and will enable researchers to compare their theories with these tests as well as with the previous 1819 tests $[1,2]$. The database also compares the test failure loads with the recommendations of Eurocode 4 [3].

The majority of tests were on composite columns with axial loads applied but in a number of cases the load was applied eccentrically at the ends so causing a moment in the column.

The properties ( $D$ (or $h \& b$ ), $t, f_{y}, E_{s}, f_{\text {cyl }}$, $E_{c}, L$, and, when eccentric load was applied, $\left.e_{t}, e_{b}\right)$ are given for each test as well as the failure load (Test) and Eurocode 4 prediction of the column's ultimate strength (EC4). Associated with this database is a word document listing all 51 references to the Papers from where the data has been obtained. There are also files summarizing all tests and giving graphs as well as the author's comments and conclusions.

The Excel files provide a database which covers: circular section short $(\mathrm{L} / \mathrm{D}<4)$ columns without moment (file aa); long columns without moment (file bb); circular columns with moment (file cc); rectangular section columns mainly long $(\mathrm{L} / \mathrm{b}>4)$ plus some short without moment (file ee) and with moment (file gg). The file referencing corresponds to the earlier database [2] when tests were grouped in a similar fashion (a, b, $\mathrm{c}, \mathrm{e}, \mathrm{g})$. Table 1 is a summary of the tests.

\section{Eurocode 4}

Composite columns and composite compression members is covered in Section 6.7 of Eurocode 4 (EC4) and a discussion of these clauses is given in Ref. 1. The principal limitations as far as CFST columns are concerned are that the steel grade should be $\mathrm{S} 235$ to S460 (f $235-460 \mathrm{~N} / \mathrm{mm}^{2}$ ) and normal weight concrete of strength classes C20/25 to C50/60 (cylinder strength $20-50$ $\mathrm{N} / \mathrm{mm}^{2}$ ). The previous paper [1] showed that, for circular section columns, the concrete cylinder strength could be safely extended to $75 \mathrm{~N} / \mathrm{mm}^{2}$ (cube $94 \mathrm{~N} / \mathrm{mm}^{2}$ ) and to $60 \mathrm{~N} / \mathrm{mm}^{2}$ for rectangular section columns and the results reported in this paper confirm this. For circular section CFST columns 'eta' enhancement factors can be applied to the concrete strength to allow for the enhanced failure stress caused by the confining effect of the steel tube producing a triaxial compressive state of stress in the concrete. For rectangular section CFST columns the failure stress is taken as the cylinder strength, without the 0.85 factor which is applied to unconfined concrete to relate the cylinder strength to the uniaxial strength.

When there is a moment on the column two methods of analysis are allowed in EC4. A 'simplified' method in which the secondorder effects (P- $\Delta$ effect and member imperfections) are allowed for by multiplying the first-order applied moments by a factor, 'k', (greater than unity); and more exact methods where the second-order effect, the lateral deflection due to end moment, is analysed and allowed for; imperfections can also be included. In the tests reported in the database the moment is caused by applying the end load eccentric to the axis of the column. In the simplified method the calculated resistance moment has been divided by the ' $\mathrm{k}$ ' factor to compare with the test result (rather than factoring the test result by ' $\mathrm{k}$ ') and this predicted failure load is compared with the test result at the same axial load/moment ratio as used in the test.

\section{Comparison of the tests with EC4}

A summary of the results is shown in Table 1 where the ratio of the test failure load (Test) divided by the EC4 prediction, with material partial safety factors of unity, is shown for each group of tests. It will be seen that for each group of tests the average Test/EC4 is greater than one, implying a 'safe' prediction, with the overall average for all 473 tests being 1.10 . 
Table 1. Summary of test results.

\begin{tabular}{|l|c|c|c|}
\hline \multicolumn{1}{|c|}{ Type } & No & $\begin{array}{c}\text { Av. } \\
\text { Test/EC4 }\end{array}$ & $\begin{array}{c}\text { Tests } \\
\text { T/EC4 } \\
<1\end{array}$ \\
\hline Short circular & 24 & $\mathbf{1 . 0 4}$ & $21 \%$ \\
\hline Long circular & 87 & $\mathbf{1 . 0 9}$ & $18 \%$ \\
\hline Short Rect. & 35 & $\mathbf{1 . 0 4}$ & $48 \%$ \\
\hline Long Rect. & 100 & $\mathbf{1 . 1 9}$ & $29 \%$ \\
\hline $\begin{array}{l}\text { Circular with M } \\
\text { k factor analysis }\end{array}$ & 114 & $\mathbf{1 . 1 2}$ & $24 \%$ \\
\hline $\begin{array}{l}\text { Circular with M } \\
2^{\text {nd }} \text { ord. analysis }\end{array}$ & 114 & $\mathbf{1 . 2 9}$ & $10 \%$ \\
\hline $\begin{array}{l}\text { Rect. with M } \\
\text { k factor analysis }\end{array}$ & 113 & $\mathbf{1 . 0 5}$ & $28 \%$ \\
\hline $\begin{array}{l}\text { Rect. with M } \\
2^{\text {nd }} \text { ord. analysis }\end{array}$ & 113 & $\mathbf{1 . 2 8}$ & $10 \%$ \\
\hline \multicolumn{1}{|c|}{ Total } & $\mathbf{4 7 3}$ & $\mathbf{1 . 1 0}$ & $26 \%$ \\
\hline \multicolumn{2}{|c|}{} \\
\hline
\end{tabular}

For tests with an end moment (M) the result is shown for both the ' $\mathrm{k}$ ' factor method of analysis and for the $2^{\text {nd }}$ order method allowing for imperfections as suggested by the Code. This shows that this $2^{\text {nd }}$ order method gives 'safer' results (larger Test/EC4 ratio). However, the number of tests where the Test/EC4 ratio is less than one is high (the $\%$ is given in the fourth column) and this high percentage could be considered unacceptable.

A number of researchers gave the same concrete strength for a whole series of tests and this implies that they only did one set of cylinder (or cube) tests for the whole series; this is not good practice as, even if the same mix is used, the tests were done on different days so the age and thus strength of the concrete would have been different.

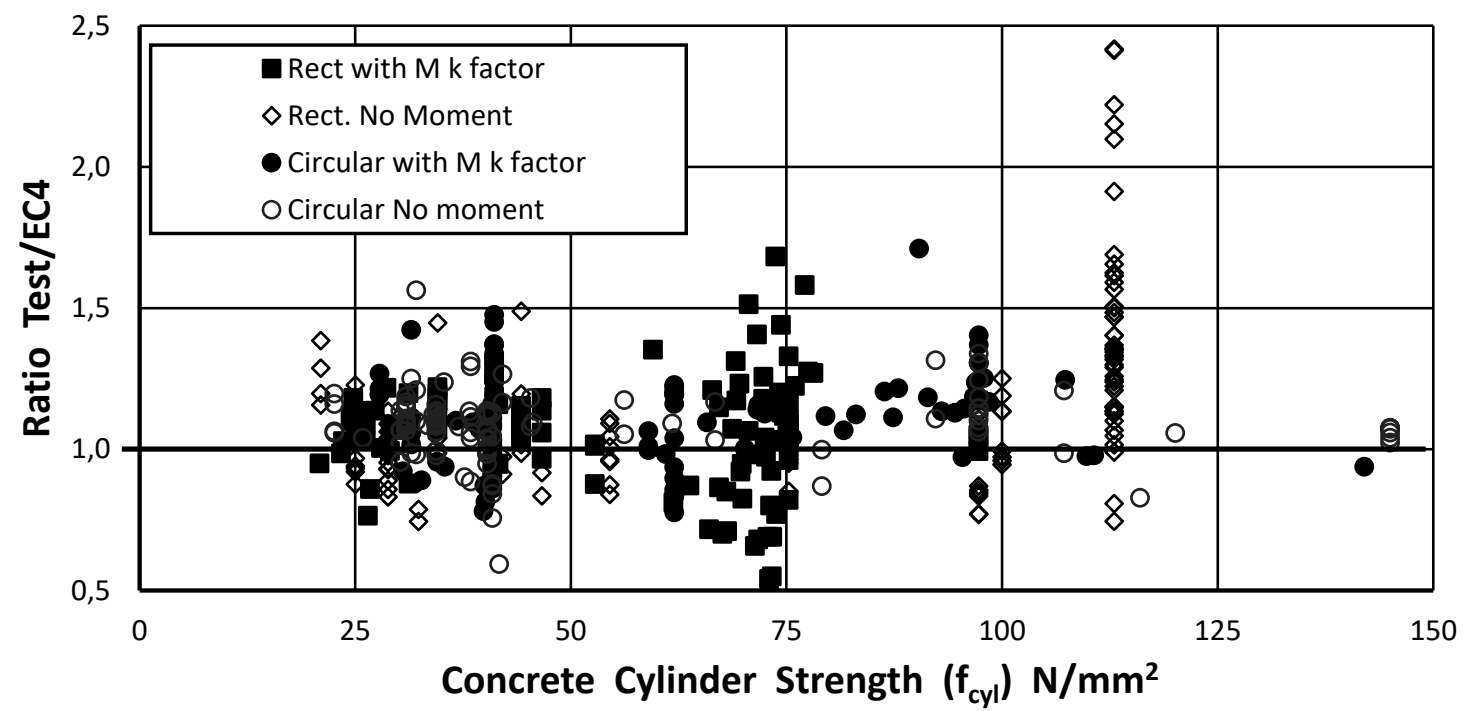

Fig. 1. Ratio of Test/EC4 versus concrete cylinder strength for all 473 tests.

Test is the failure load in the test and 'EC4' the prediction by Eurocode 4 using the ' $\mathrm{k}$ ' factor analysis.

Fig. 1 shows that concrete strength does not affect the ratio of Test/EC4 as there is no trend as the concrete strength increases.

There were 114 tests on circular section columns which used a concrete strength greater than $75 \mathrm{~N} / \mathrm{mm}^{2}$ and they had an average Test/EC4 of 1.16 (compared with 1.10 for all 225 circular columns).

There were 100 tests on rectangular section columns which used a concrete strength greater than $75 \mathrm{~N} / \mathrm{mm}^{2}$ and they had an average Test/EC4 of 1.22 (compared with 1.10 for all 248 rectangular columns).
Thus, in the author's opinion, the Code upper limit of a cylinder strength of 50 $\mathrm{N} / \mathrm{mm}^{2}$ could safely be raised to $125 \mathrm{~N} / \mathrm{mm}^{2}$.

The figure does show the considerable scatter of results for all types of test both with and without an end moment though there are more rectangular section columns failing to achieve the Eurocode 4 prediction than there are circular section columns.

Fig. 2 compares this same Test/EC4 ratio against the ratio of length/diameter for circular section columns, and length/breadth for rectangular columns, as this is one measure of their slenderness. 


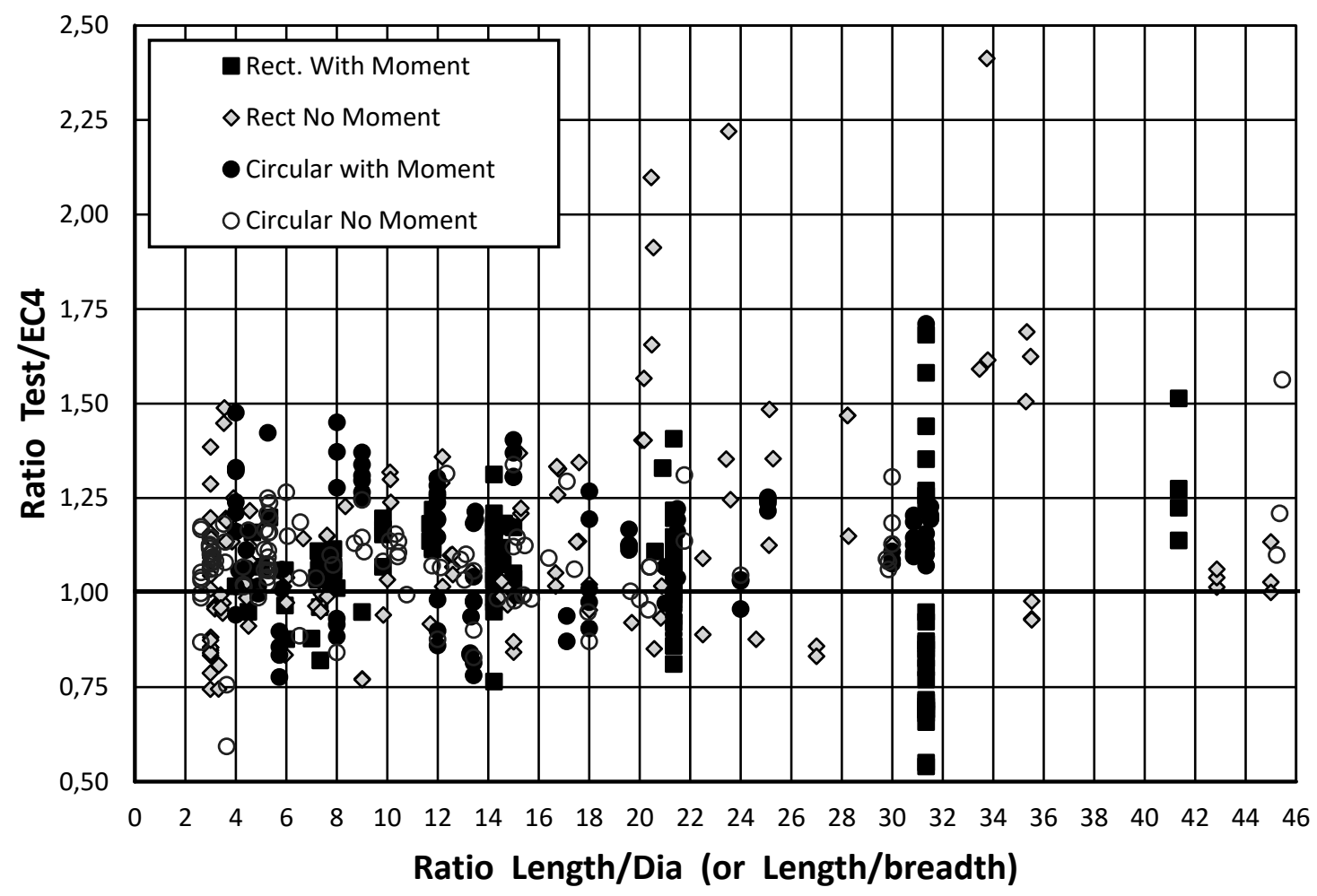

Fig. 2. Ratio of Test/EC4 versus Length/Dia (or Length/breadth) for all 473 tests.

Fig. 2 shows the slight tendency for the Code to give safer predictions as the columns become more slender; the author considers this to be desirable.

Fig. 2 also shows that the effect of slenderness gives no difference in the results between circular or rectangular section columns or between those with and without an applied end moment.

As seen with Fig. 1, Fig. 2 also shows the considerable scatter of results.

\section{Conclusions}

This paper gives researchers access to new data on tests done between 2007 and 2017 on concrete-filled steel tubes of both circular and rectangular cross-section and compares the test failure load with the predictions given in Eurocode 4.

Eurocode 4 is a reasonable predictor of the strength of composite columns with and without end moment and the author considers it can be used with confidence for the design of such columns. However, the number of tests which did not quite reach the predicted failure load (26\%) is worrying and may be considered unacceptable.

The tests show (Fig. 1) that the limitation on concrete cylinder strength in the Eurocode $4\left(\mathrm{f}_{\text {cyl }}<50 \mathrm{~N} / \mathrm{mm}^{2}\right)$ could safely be extended to $125 \mathrm{~N} / \mathrm{mm}^{2}$.

For columns with an end moment the ' $\mathrm{k}$ ' factor method, that is given in Eurocode 4, is satisfactory though using a 'second order' analysis gives 'safer' results as there are fewer predictions $(10 \%)$ that are greater than the test failure load while for the ' $\mathrm{k}$ ' factor method this figure is about $26 \%$.

There has been adequate testing of both circular and rectangular section composite columns with and without an end moment but more testing of rectangular section columns under biaxial bending is desirable (only 11 tests to date).

\section{Acknowledgements}

Prof. Mark Denavit and his colleagues at the University of Tennessee, Knoxville, are thanked for the use of their files from which the data for the Database has been obtained. 


\section{References}

[1] Goode C. D. Composite columns - 1819 tests on concrete-filled steel tube columns compared with Eurocode 4. The Structural Engineer 2008; 86(16): 33-38.

[2] Website at Bradford University: https://www.bradford.ac.uk/research/rktcentrres/centre-for-sustainableenvironment/associationforsteel-concrete compositestructures/columnsdatabase Database is also available from Goode, email: cdgoode@mypostoffice.co.uk
[3] BS EN 1994-1-1:2004: Eurocode 4. Design of composite Steel and concrete structures Part 1.1: General rules and rules for buildings 2004; British Standards Institution, Milton Keynes.

[4] Denavit M. Database on 'Website': https://github.com/denavit/CompositeColumn-database/commit /471b5f9597ba13197acbfd82306556a936f0 $579 f$ 